\title{
Examining participant perceptions of an interprofessional simulation-based trauma team training for medical and nursing students
}

\begin{abstract}
High quality care relies on interprofessional teamwork. We developed a short simulation-based course for final year medical, nursing and nursing anaesthesia students, using scenarios from emergency medicine. The aim of this paper is to describe the adaptation of an interprofessional simulation course in an undergraduate setting and to report participants' experiences with the course and students' learning outcomes. We evaluated the course collecting responses from students through questionnaires with both closed-ended and open-ended questions, supplemented by the facilitators' assessment of students' performance. Our data is based on responses from 310 students and 16 facilitators who contributed through three evaluation phases. In the analysis, we found that students reported emotional activation and learning outcomes within the domains self-insight and stress management, understanding of the leadership role, insight into teamwork, and skills in team communication. In subsequent questionnaire studies students reported having gained insights about communication, teamwork and leadership, and they believed they would be better leaders of teams and/or team members after having completed the course. Facilitators' observations suggested a progress in students' non-technical skills during the course. The facilitators observed that nursing anaesthesia students seemed to be more comfortable in finding their role in the team than the two other groups. In conclusion, we found that an interprofessional simulation-based emergency team training course with a focus on leadership, communication and teamwork, was feasible to run on a regular basis for large groups of students. The course improved the students' team skills and received a favourable evaluation from both students and faculty.
\end{abstract}


Keywords: Interprofessional education, team training, simulation, undergraduate education, teamwork, leadership, communication, acute medicine

\section{Introduction}

High quality care relies increasingly on interprofessional teams, however reviews have shown that implementation of interprofessional education (IPE) in undergraduate education lags behind (e.g. Abu-Rish et al., 2012; Gilligan, Outram, \& Levett-Jones, 2014). The Institute of Medicine as well as current guidelines in emergency medicine state that all health professionals should be trained to deliver patient-centered care as members of interprofessional team (Greif et al., 2015; Greiner $\&$ Knebel, 2003). The Institute of Medicine further emphasized the importance of IPE in their consensus report on measuring the impact of IPE calling for more research to strengthen the evidence base and study the impact on patient outcomes (Institute of Medicine, 2015).

The literature is abundant with reports that situational awareness, efficient communication and leadership, often referred to as "non-technical skills", are essential factors in well-functioning trauma teams (Cole \& Crichton, 2006; Hjortdahl, Ringen, Naess, \& Wisborg, 2009; Hoyer, Christensen, \& Eika, 2009; Kohn, Corrigan, \& Donaldson, 2000; The Joint Commission, 2015). Simulation studies also suggest that effective communication and non-technical skills in teams during diagnostic processes leads to quicker and more correct diagnosis, an increase in completed clinical tasks and quicker surgical crisis resolution (Doumouras et al., 2017; Shrader, Kern, Zoller, \& Blue, 2013; Tschan et al., 2009). Effective teamwork skills have indeed been associated with more effective real world medical management of emergencies (Cooper \& Wakelam, 1999; Westli, Johnsen, Eid, Rasten, \& Brattebø, 
2010). In retrospective analyses of real clinical events lack of clear leadership and poor communication have been found to be a factor in $70 \%$ of perinatal deaths and injuries in acute pediatric situations and the main factor in almost half of 73 examined fatal medical events from a range of specialties (Thomas et al., 2007; Uramatsu et al., 2017).

Simulation-enhanced IPE has been advocated as part of the solution to the above mentioned patient safety challenges (Palaganas, Epps, \& Raemer, 2014; Wong, Gang, Szyld, \& Mahoney, 2016). In general, simulation is increasingly used in education of healthcare professionals as shown in several surveys (Bagnasco et al., 2014; Ericson, Masiello, \& Bolinder, 2012; Lateef, 2010; Nestel et al., 2011; Stewart, Kennedy, \& Cuene-Grandidier, 2010). Systematic reviews have shown that wellintegrated simulation with a focus on feedback and debriefing facilitates learning of both technical and non-technical skills in medical education (Fung et al., 2015; Issenberg, McGaghie, Petrusa, Lee Gordon, \& Scalese, 2005; Motola, Devine, Chung, Sullivan, \& Issenberg, 2013). Team training and simulation exercises have also been shown to be effective in teaching non-technical skills in postgraduate education, both with regards to interpersonal skills, e.g. communication, team working and leadership, and cognitive skills, e.g. situational awareness, planning, decision making and task management (Boet et al., 2016; Hinde, Gale, Anderson, Roberts, \& Sice, 2016; Hunziker et al., 2010; Morey et al., 2002; Shapiro et al., 2004; Stephens, Hunningher, Mills, \& Freeth, 2016; Yee et al., 2005). Despite this evidence, at the time of the implementation of the course, which we report on in this paper, reviews of IPE found only one and four studies, respectively, reporting using simulation in pre-licensure education (Reeves et al., 2011; Zhang, Thompson, \& Miller, 2011). Likewise, the importance of non-technical skills to avoid medical errors has generally not been 
given priority in the curricula of health professions as found by several authors

(Chakraborti, Boonyasai, Wright, \& Kern, 2008; General Medical Council, 2013; Lo, 2011). Fortunately, more recent reviews of simulation-based IPE finds increasing interest and a steadily increasing number of high-quality studies with the majority of the pre-licensure IPE studies published after 2010 (Palaganas, Brunette, \& Winslow, 2016; Reeves, Fletcher, et al., 2016; You, Malik, Scott, \& Fung, 2017).

\section{Background}

The Faculty of Medicine at the University of Oslo and the Department of Nursing at Oslo and Akershus University College of Applied Sciences decided to implement a one-day team training course for medical students, nursing students and students in nursing anaesthesia, in which high-fidelity simulation was used to train team skills in an emergency medicine setting. The main aim of this paper is to describe the adaptation and implementation of the BEST (Better and Systematic Team Training) course to students (Student-BEST) and to report the participants' experiences and the students' learning outcomes.

\section{The Student-BEST course}

This course was developed by faculty from the University of Oslo and the Oslo and Akershus University College of Applied Sciences. The BEST-approach widely used in postgraduate training in Norway was originally developed to provide systematic training of team skills for fully licensed members of trauma team in the workplace, so it was necessary with adjustments to the undergraduate setting (Wisborg et al., 2008; Wisborg, Brattebø, Brattebø, \& Brinchmann-Hansen, 2006): . We reduced complexity in the student teams by reducing the number of professions present to three: medical and nursing students and student in nursing anaesthesia. This 
was also convenient from a logistical perspective and helped ease the matching of timetables of all students. The original BEST-approach also incorporated in-situ simulations using low-fidelity manikins. The students did not have a common workplace and the course was therefore carried out in the practice floor/simulation floor at the University College in contrast to the workplace resuscitation rooms. The pilot rounds indicated that using high-fidelity manikins allowed teams to engage more rapidly in the simulations. Research supports using high-fidelity simulations in inexperienced participants (Maran \& Glavin, 2003), and we thus adapted the course to use high-fidelity manikins (SimMan and Resusci Anne Skilltrainer, Laerdal Medical, Stavanger, Norway) allowing for full clinical examination of blood pressure, respirations sounds, cardiac rhythms as well as possibilities for standard resuscitative procedures. Personnel from the Foundation for BEST contributed with didactic advice during the initial planning stages and pilots.

\section{The students}

The course was piloted in several rounds and was subsequently implemented in full scale as a mandatory course for medical students and students in nursing anaesthesia, supplemented by voluntary enrolment of nursing students. Both medical and nursing students were at the time of the course only a few weeks away from final exams and within 1-2 months would be taking their first jobs with independent responsibility, albeit in junior positions. The students in nursing anaesthesia were also between a few weeks and half a year before being fully licensed nurse anaesthetists after which they would typically go on to work with full responsibility in intensive care and operating room environments providing anaesthesia to patients, including advanced airway management and pre-, per- and postoperative monitoring of patients undergoing surgery. Generally working independently in low risk patients and 
commonly in close collaboration with anaesthetist doctors in higher risk/more complicated cases. All students in nursing anaesthesia would have between 2-4 years of experience working as registered nurses before being admitted to the nurse anaesthetist master program.

\section{Facilitators and logistics}

All Student-BEST facilitators had clinical and teaching experience with trauma and emergency medicine, and they completed a three-hour workshop on the BEST-principles of simulation and debriefing before the pilot rounds. Each team consisted of 4 medical students, 2-3 nursing students and 0-2 students in nursing anaesthesia. Each team performed four video-recorded simulations in real time without interruptions. All videos were deleted in the presence of the team at the end of each debriefing session. Two facilitators, one from each institution, remained stationary at each station to run the simulation and debriefing, while the team rotated from station to station. The facilitators were allowed to adapt the difficulty level of the clinical scenario to the performance of the team during the simulation as the main objective of the simulation was to provide a realistic setting for the team to interact within and not to test technical skills specifically. On each course day five teams participated in four 60 minutes sessions consisting of simulation (15-20 minutes) immediately followed by debriefing (40-45 minutes), alternating with four interactive lecture sessions of 30 minutes including an evaluation session. All lectures were focused on the interprofessional aspects of the day, including roles in the team, communication between team members, leadership and tools for efficient teamwork. The course day is described in detail in Appendix 1 in the online supplementary material. 
The role as team leader rotated and was assigned to a new medical student in the team in each simulation. After each simulation facilitators led a structured debriefing session, using the video recording of the team performance as a resource for reflection in the team, focusing on communication, leadership and intra- and interprofessional collaboration. All team members were invited to contribute, and members with less "formal" influence in the team were asked to comment first, e.g. nursing students commenting before nursing anaesthesia students, who spoke before medical students. The team leader invariably spoke last. At the end of each debriefing each individual team member had to state an area for improvement. Efforts were made to make each consecutive simulation slightly more challenging to enhance the principle of spiral learning. The course, when made mandatory, was taught five days in a week allowing for a capacity of 100 medical students, 50-75 nursing students and 25-50 nursing anaesthesia students per semester. The practice floor at the University College already had all necessary technical facilities making manpower the largest cost contributor as each day 10 facilitators were present to run the five stations, and in addition one extra technician were readily available to solve technical troubles should they occur, as well as setting up and resetting stations between simulations.

\section{Methods}

After the implementation of the program we chose a post-intervention study design to gather questionnaire data from a total of 310 students and 16 facilitators. The first evaluation phase involved an exploration of students' learning outcomes, which was used iteratively to develop a questionnaire that was used in the second phase. In the third phase, we collected data from facilitators. 


\section{Data collection}

In the first phase, a total of 145 students (101 medical students and 44 nursing students) received a questionnaire in which they were asked to note their profession and write free-text responses to three open-ended questions: "What was your experience from the simulation and debriefing sessions?", "What were your thoughts during the course?", and "What did you learn?" Students in nursing anaesthesia did not participate in this cycle as the University College did not have a graduate class this semester.

The questionnaires used in the second and third phases were developed, evaluated and revised for face validity by three of the authors (RBJ, SFG and JCF). The questionnaires were deliberately focused on the main learning objectives in the course including communication, leadership and teamwork.

In the second phase, a total of 165 students (98 medical students, 23 students in nursing anaesthesia, 44 nursing students) responded to a 25 -items questionnaire with answers on a 5-point Likert scale, ranging from 1 (strongly disagree) to 5 (strongly agree). Students' responses were collected using an electronic polling system (Turningpoint, Turning Technologies, Youngstown, Ohio).

In the final phase, 16 out of 20 facilitators returned an electronic questionnaire in an in-house developed online data collection tool. The questionnaire included 12 statements about the facilitators' experiences with the course, students' team performance, and other aspects of simulation as a teaching modality, with answers on a 5-point Likert scale, ranging from 1 (strongly disagree) to 5 (strongly agree).

\section{Data analysis}

We used systematic text condensation (STC), a method for cross-case thematic analysis for the students' free-text responses (Malterud, 2012). We read the 
text to obtain an overall impression of students' responses and self-assessed learning outcomes, identified parts of text (meaning units), representing aspects of responses and learning, coded these, condensed the contents of each of the coded groups (emotional activation, self-insight and stress management, understanding of the leadership role, insight into teamwork, and skills in team communication), and summarized the contents of these. Three authors were involved in the analysis (RBJ, SFG and JCF). Illustrative quotes were translated from Norwegian to English.

The SPSS statistics package version 21 (IBM, New York, NY) was used to calculate descriptive statistics from the quantitative questionnaires. A Kruskal-Wallis test was used to determine if differences were significant between students with different professional backgrounds. Pairwise comparisons were performed using a Dunn's (1964) procedure with a Bonferroni correction for multiple comparisons. Statistical significance was assumed for $\mathrm{p}<0.05$.

\section{Ethical considerations}

All participants were informed that the data would be used to evaluate the course, and might be published. Our data collection was part of the regular quality assurance of teaching at the University of Oslo and the University College, and the project approved by the educational leadership. We did not collect personal identifiable data that would have required approval from the Data Protection Official for Research.

\section{Results}

\section{Phase 1: Students'free-text comments}

In the analysis of these data, we found that students reported emotional activation and learning outcomes within four themes: Self-insight and stress 
management, understanding of the leadership role, insight into teamwork, and skills in team communication.

Students described the emotional activation they experienced in the simulations in different ways. Positive descriptions included "exciting", "fun", "want to try more", "inspiring", "fantastic", and "feeling of mastery". Among negative emotions mentioned by students were "stressful", "scary", "challenging", "demanding" or "embarrassing".

Self-insight and stress management were mentioned by many students as a learning outcome. For example, one student noted, "I became aware of the need to improve. In the meantime, it was nice to see that I do other things well" (medical student (M)). Students reported becoming aware that they lacked situational awareness: "I think I disconnected and acted by reflex or instinct. A lot of the time, I did not think at all. I should probably reflect on this, for my own sake" (M). Students reported that they learned to cope with stress: "I learned to relate to acute, stressful situations, and how I cope" (nursing student (N)).

Understanding more about the team leadership role was a common theme, and students reported learning that leadership was crucial in emergency teams: "A good leader is important - then everyone can do their task well" (N). Several students had learned that the team leader had to step back, and "to use the team and the competency in it" (M). Some students had learned that the leader had to stay calm and keep oversight over the situation, and plan the next step for the team: "The most difficult with being the leader is to know what to do and what to order next" (M).

Students reported gaining insight into teamwork. A student wrote: "Individual experience does not mean as much as functioning like a team" (M). Students had learned the importance of sticking to their role instead of interfering with other team 
members' tasks. They also reported learning how to be proactive in their role: "I reflected on how much a nurse can prepare and make ready in advance" $(\mathrm{N})$.

Students reported learning the value of communication techniques such as “closed-loop" and doing situational summaries with loud and clear messages. Students had observed the effects of poor communication from both leaders and team members: "It was difficult to give clear messages when I was unclear about the treatment plan" (M). Persistent use of the receiver's name or role was always noted as valuable. They reported learning the importance of communication with the patient: "Listen to the patient first - as the patient can lose conscience!" (M)

\section{Phase 2: Student questionnaires}

The students responded positively to most statements on the questionnaire (Table 1). The didactic lecture on debriefing and feedback was valued higher by nursing students compared with medical students. Medical students found the feedback from facilitators less useful than the nursing students. There were no significant differences between the two groups for questions concerning communication, though it is worth noting that the question relating to the five-step assertive statement process (Appendix 1) received the lowest mean score of 3.5. Medical students' scores were significantly higher on questions regarding leadership and the students in nursing anaesthesia found the use of role-tagged vests more useful than the medical students.

\section{INSERT TABLE 1 ABOUT HERE}

\section{Phase 3: Facilitator questionnaires}

The facilitators generally agreed that students' skills in leadership and communication improved during the day of simulation (Table 2). The facilitators 
reported that students mastered the challenges, and scored performances of nursing anaesthesia students higher than other professions with a score of 4.8 vs. 4.3 (medical students) and 3.8 (nursing students). The facilitators also found that nursing anaesthesia students struggled less with finding their role with mean scores of $2.3 \mathrm{vs}$. 3.2 (medical students) and 4.1 (nursing students).

\section{INSERT TABLE 2 ABOUT HERE}

\section{Discussion}

As presented above, we found in the free-text data that students reported experiencing a high degree of emotional activation during the simulation exercises. Such emotional activation or arousal in the participants is a common finding in simulation studies (Clarke et al., 2014a; Meurling, Hedman, Sandahl, Fellander-Tsai, \& Wallin, 2013; Murray \& Foster, 2000). Emotional arousal may be viewed as a desired feature as it has been shown to facilitate long-term learning in both animal and human studies through amygdala involvement, however it is also known that too much stress may affect memory retrieval negatively (Cahill \& McGaugh, 1998; Vogel \& Schwabe, 2016). Our finding of both negative and positive reactions highlights this paradox that must be taken into account when deciding how much stress to put in to a simulation scenario. This might be subject for further research, especially as other researchers have shown that students will react differently to the same simulation experience depending on personal factors such as previous clinical or simulation experience and their role in the team (Clarke et al., 2014b).

We also found that students strongly agreed that briefings, summaries and closed-loop communication were important, and they reported having gained insights about communication, teamwork and leadership. Most importantly, they believed they 
would be better leaders of teams and/or team members after having completed the course. These findings were further confirmed by the facilitators' observation of progress in students' non-technical skills during the course. Our findings are in line with findings using the BEST methodology in postgraduate education (Wisborg et al., 2006).

The facilitator data suggest differences between professional groups, and that nursing anaesthesia students seemed to be more comfortable in finding their role in the team than the two other groups. These intergroup differences in role functioning may reflect two aspects of the student groups. First, nursing anaesthesia students were usually assigned to their regular and clearly defined role in charge of airway management. For the nursing students, the initial instructions were often less clear, such as "helping the examining doctor with equipment". Second, nursing anaesthesia students had requirements of clinical experience as regular nurses before being admitted to study nursing anaesthesia providing them with a broader experience base, while the nursing students had clinical experience only through short-term clinical work placements. We believe this difference between the professions represented an added value to the simulation scenarios as it mirrored the natural variability in experience often seen in real clinical teams (Härgestam, Lindkvist, Brulin, Jacobsson, \& Hultin, 2013; Ringen, Hjortdahl, \& Wisborg, 2011). By being able to address how to find their roles in a team during the simulation and the debriefing, the students may hopefully gain knowledge on how to better mitigate being either more or less experienced than other team members in the future. We also believe it a strength in general, that all students acted in their "native" role and were not assigned a different role or profession, which has been found previously to affect the ability of participants to fully engage in a scenario (van Soeren et al., 2011). 
We found that medical students significantly agreed more than the other professions to be better suited to lead future teams, not unexpectedly as they were assigned the team leader role during the simulations. However, the two other groups were also positive to the statement about having learned how to take leadership in teams. We believe this to be a highly desirable finding, as both nurses and nurse anaesthetists will often work in various team settings without doctors and be called upon to take charge during medical emergencies.

Our experiences with our course suggest that interprofessional team training is feasible in the undergraduate setting. We believe several factors, outlined below, contributed to a successful development and implementation of an interprofessional course at our institutions, quite in line with factors identified in a recent study from the Netherlands (de Vries-Erich, Reuchlin, de Maaijer, \& van de Ridder, 2017): We chose the established, and in Norway widely used, BEST-methodology for team training and Student-BEST benefited from assistance provided by the BESTfoundation in the initial phases (Wisborg et al., 2006; Wisborg, Ronning, Beck, \& Brattebo, 2003). This familiarity with the BEST concept among the faculty combined with a positive attitude to training non-technical skills helped gain momentum in the pilot rounds. We think engagement of enthusiastic faculty from all professional groups involved was crucial, as they were able to influence how to make the course benefit their students during course development. This founded a culture for mutual respect and interprofessional cooperation, which has indeed been identified as an important element in other successful courses (Bridges, Davidson, Odegard, Maki, \& Tomkowiak, 2011). Sufficient resources are crucial for simulation-based courses, which are more resource demanding than didactic lectures (Buckley et al., 2012). By starting with a small pilot that provided "proof of concept", positive reactions from 
faculty and students subsequently made it easier to argue for resources for a full-scale course. Arguably, we also benefited from good timing as the course development coincided with the implementation of a module on evidence-based medicine, leadership and quality improvement(Frich, Gran, Vandvik, Gulbrandsen, \& Hjortdahl, 2012). Additionally, a restructuring of the module in emergency medicine freed teaching resources and a change of final exams for the medical students to Objective Structured Clinical Exams called for more practical exercises.

Faculty development has been shown to be a crucial, however often overlooked, element of successful IPE courses (Egan-Lee, E., Baker, L., Tobin, Hollenberg, E., Dematteo, D., \& Reeves, 2011; Motola et al., 2013; Reeves, Pelone, et al., 2016). Initially, we held a facilitator workshop with instructors from the BESTfoundation. Experienced instructors from the foundation also observed simulations and debriefings during the first cycles of the course and provided feedback directly to the facilitators during breaks. Later, we encouraged facilitators to attend external courses by the BEST-foundation or other courses on non-technical skills in simulation settings. Finally, when new and/or inexperienced facilitators were introduced to the course they were paired with experienced facilitators with formal training in facilitation.

We acknowledge that our study has limitations. We have relied on selfassessment data, and we did not objectively measure improvement in team skills other than by observation from the facilitators. Thus, our findings fall in the first two levels of Kirkpatrick's (1996) outcomes model and it would not be prudent to extrapolate the results with any certainty to behaviour and improvement on patient outcomes in the workplace. We used a purpose designed questionnaire in the second and third cycle which were validated for face validity regarding the main learning objectives, but not 
subjected to more formal validation by identifying underlying components or internal consistency. We did try to identify suitable questionnaires in the literature but, as other authors have published, found them hard to find, rarely fully validated and lacking in face validity in the areas we were interested in (Gillan, Lovrics, Halpern, Wiljer, \& Harnett, 2011; Thannhauser, Russell-Mayhew, \& Scott, 2010). With these limitations in mind, the Student-BEST course seemed efficient in teaching team skills, with results in line with other studies(Brashers et al., 2016; Stephens et al., 2016), but the limited follow-up time call for modesty. The BEST methodology has previously been shown to effectively increase the participants perceived knowledge and confidence in teamwork and improve team performance after 6 months in trauma teams (Wisborg et al., 2008), but we did not investigate if the Student-BEST course had a corresponding long-term effect. In a similar setting, however, a one-day course with three simulations for residents led to significant improvements in non-technical skills, which were retained after one and two months (Yee et al., 2005). Still, it would have been interesting to evaluate changes in behaviour of participants over time. It is uncommon for courses in the undergraduate setting to consistently include several professions (Chakraborti et al., 2008) and a longer follow-up period after the transition for student to licensed health care professional would have added valuable data and might be pursued in future studies, preferably using a validated outcome tool for both team and individual performance such as the Team Performance Scale and the individual Teamwork Observation and Feedback Tool (Sigalet et al., 2013; Thistlethwaite et al., 2016). Pertinent to the present course, we do believe that the presented positive results indicate an increased awareness of non-technical skills, which could translate into a less error prone team behaviour. Actual clinical learning was not a main objective of the course, and as such we did not use resources assessing 
clinical learning. However, the first question on the student questionnaire did capture that the students regarded the course as useful in learning about emergency treatment as compared to traditional lectures. A more formal evaluation of clinical learning could have strengthened the argument further in favour of using the rather extensive resources involved in simulation-based IPE.

\section{Concluding comments}

We found that a simulation-based course based on methodology used in postgraduate education focused on leadership, communication and teamwork was adaptable to the undergraduate setting and feasible to teach on a regular basis for a large group of students. The implemented one-day course for final year medical, nursing and nursing anaesthesia students using scenarios from emergency medicine was associated with positive learning outcomes.

\section{Declaration of interests}

The authors declare that there are no competing financial or non-financial interests in relation to this study.

\section{References}

Abu-Rish, E., Kim, S., Choe, L., Varpio, L., Malik, E., White, A. a, ... Zierler, B. (2012). Current trends in interprofessional education of health sciences students: a literature review. Journal of Interprofessional Care, 26(6), 444-51. doi:10.3109/13561820.2012.715604

Bagnasco, A., Pagnucci, N., Tolotti, A., Rosa, F., Torre, G., \& Sasso, L. (2014). The role of simulation in developing communication and gestural skills in medical students. BMC Medical Education, 14(1), 106. doi:10.1186/1472-6920-14-106

Boet, S., Pigford, A.-A., Fitzsimmons, A., Reeves, S., Triby, E., \& Bould, M. D. (2016). Interprofessional team debriefings with or without an instructor after a simulated crisis scenario: An exploratory case study. Journal of Interprofessional 
Care, 30(6), 1-9. doi:10.1080/13561820.2016.1181616

Brashers, V., Erickson, J. M., Blackhall, L., Owen, J. A., Thomas, S. M., \& Conaway, M. R. (2016). Measuring the impact of clinically relevant interprofessional education on undergraduate medical and nursing student competencies: A longitudinal mixed methods approach. Journal of Interprofessional Care, 30(4), 448-457. doi:10.3109/13561820.2016.1162139

Bridges, D. R., Davidson, R. A., Odegard, P. S., Maki, I. V, \& Tomkowiak, J. (2011). Interprofessional collaboration: three best practice models of interprofessional education. Medical Education Online, 16. doi:10.3402/meo.v16i0.6035

Buckley, S., Hensman, M., Thomas, S., Dudley, R., Nevin, G., \& Coleman, J. (2012). Developing interprofessional simulation in the undergraduate setting: Experience with five different professional groups. Journal of Interprofessional Care. doi:10.3109/13561820.2012.685993

Cahill, L., \& McGaugh, J. L. (1998). Mechanisms of emotional arousal and lasting declarative memory. Trends in Neurosciences, 21(7), 294-299. doi:10.1016/S0166-2236(97)01214-9

Chakraborti, C., Boonyasai, R. T., Wright, S. M., \& Kern, D. E. (2008). A systematic review of teamwork training interventions in medical student and resident education. Journal of General Internal Medicine, 23(6), 846-53. doi:10.1007/s11606-008-0600-6

Clarke, S., Horeczko, T., Cotton, D., Bair, A., Huang, G., Sacks, H., ... Bandiera, G. (2014a). Heart rate, anxiety and performance of residents during a simulated critical clinical encounter: a pilot study. BMC Medical Education, 14(1), 153. doi:10.1186/1472-6920-14-153

Clarke, S., Horeczko, T., Cotton, D., Bair, A., Huang, G., Sacks, H., ... Bandiera, G. (2014b). Heart rate, anxiety and performance of residents during a simulated critical clinical encounter: a pilot study. BMC Medical Education, 14(1), 153. doi:10.1186/1472-6920-14-153

Cole, E., \& Crichton, N. (2006). The culture of a trauma team in relation to human factors. Journal of Clinical Nursing, 15(10), 1257-1266. doi:10.1111/j.13652702.2006.01566.x

Cooper, S., \& Wakelam, A. (1999). Leadership of resuscitation teams: "Lighthouse Leadership'. Resuscitation, 42(1), 27-45. doi:10.1016/S0300-9572(99)00080-5 de Vries-Erich, J., Reuchlin, K., de Maaijer, P., \& van de Ridder, J. M. M. (2017). 
Identifying facilitators and barriers for implementation of interprofessional education: Perspectives from medical educators in the Netherlands. Journal of Interprofessional Care, 31(2), 170-174. doi:10.1080/13561820.2016.1261099

Doumouras, A. G., Hamidi, M., Lung, K., Tarola, C. L., Tsao, M. W., Scott, J. W., ... Yule, S. (2017). Non-technical skills of surgeons and anaesthetists in simulated operating theatre crises. British Journal of Surgery. doi:10.1002/bjs.10526

Egan-Lee, E., Baker, L., Tobin, S., Hollenberg, E., Dematteo, D., \&, \& Reeves, S. (2011). Neophyte facilitator experiences of interprofessional education: implications for faculty development. Journal of Interprofessional Care, 25(5), 333-8. doi:10.3109/13561820.2011.562331

Ericson, A., Masiello, I., \& Bolinder, G. (2012). Interprofessional clinical training for undergraduate students in an emergency department setting. Journal of Interprofessional Care, 26(4), 319-25. doi:10.3109/13561820.2012.676109

Frich, J. C., Gran, S. F., Vandvik, P. O., Gulbrandsen, P., \& Hjortdahl, P. (2012). Knowledge, leadership and quality in the medical school curriculum. Tidsskrift for Den Norske Laegeforening : Tidsskrift for Praktisk Medicin, Ny Roekke, 132(15), 1768-71. doi:10.4045/tidsskr.12.0511

Fung, L., Boet, S., Bould, M. D., Qosa, H., Perrier, L., Tricco, A., ... Reeves, S. (2015). Impact of crisis resource management simulation-based training for interprofessional and interdisciplinary teams: A systematic review. Journal of Interprofessional Care, 29(5), 433-444. doi:10.3109/13561820.2015.1017555

General Medical Council. (2013). Regional review of medical education and training in London: 2012-13. Manchester, UK.

Gillan, C., Lovrics, E., Halpern, E., Wiljer, D., \& Harnett, N. (2011). The evaluation of learner outcomes in interprofessional continuing education: A literature review and an analysis of survey instruments. Medical Teacher, 33(9), e461e470. doi:10.3109/0142159X.2011.587915

Gilligan, C., Outram, S., \& Levett-Jones, T. (2014). Recommendations from recent graduates in medicine, nursing and pharmacy on improving interprofessional education in university programs: a qualitative study. BMC Medical Education, 14(1), 52. doi:10.1186/1472-6920-14-52

Greif, R., Lockey, A. S., Conaghan, P., Lippert, A., De Vries, W., Monsieurs, K. G., ... Zideman, D. (2015). European Resuscitation Council Guidelines for Resuscitation 2015. Section 10. Education and implementation of resuscitation. 
Resuscitation, 95, 288-301. doi:10.1016/j.resuscitation.2015.07.032

Greiner, A. C., \& Knebel, E. (Eds.). (2003). Health professions education: a bridge to quality. (Vol. 65). Washington D.C.: National Academy Press. doi:10.17226/10681

Hinde, T., Gale, T., Anderson, I., Roberts, M., \& Sice, P. (2016). A study to assess the influence of interprofessional point of care simulation training on safety culture in the operating theatre environment of a university teaching hospital. Journal of Interprofessional Care, 30(2), 251-253. doi:10.3109/13561820.2015.1084277

Hjortdahl, M., Ringen, A. H., Naess, A.-C., \& Wisborg, T. (2009). Leadership is the essential non-technical skill in the trauma team--results of a qualitative study. Scandinavian Journal of Trauma, Resuscitation and Emergency Medicine, 17, 48. doi:10.1186/1757-7241-17-48

Hoyer, C. B., Christensen, E. F., \& Eika, B. (2009). Junior physician skill and behaviour in resuscitation: a simulation study. Resuscitation, 80(2), 244-248. doi:10.1016/j.resuscitation.2008.10.029

Hunziker, S., Bühlmann, C., Tschan, F., Balestra, G., Legeret, C., Schumacher, C., ... Marsch, S. (2010). Brief leadership instructions improve cardiopulmonary resuscitation in a high-fidelity simulation: a randomized controlled trial. Critical Care Medicine, 38(4), 1086-91. doi:10.1097/CCM.0b013e3181cf7383

Härgestam, M., Lindkvist, M., Brulin, C., Jacobsson, M., \& Hultin, M. (2013).

Communication in interdisciplinary teams: exploring closed-loop communication during in situ trauma team training. BMJ Open, 3(10), e003525. doi:10.1136/bmjopen-2013-003525

Institute of Medicine. (2015). Measuring the Impact of Interprofessional Education on Collaborative Practice and Patient Outcomes. doi:10.17226/21726

Issenberg, S. B., McGaghie, W. C., Petrusa, E. R., Lee Gordon, D., \& Scalese, R. J. (2005). Features and uses of high-fidelity medical simulations that lead to effective learning: a BEME systematic review. Medical Teacher, 27(1), 10-28. doi:10.1080/01421590500046924

Kirkpatrick, D. (1996). Great Ideas Revisited. Techniques for Evaluating Training Programs. Revisiting Kirkpatrick's Four-Level Model. Training and Development, 50, 54-59. Retrieved from http://search.proquest.com/docview/227011695? accountid=32799

Kohn, L. T., Corrigan, J. M., \& Donaldson, M. S. (Eds.). (2000). To Err Is Human. 
Washington, D.C.: National Academies Press. doi:10.17226/9728

Lateef, F. (2010). Simulation-based learning: Just like the real thing. Journal of Emergencies, Trauma, and Shock, 3(4), 348-52. doi:10.4103/0974-2700.70743

Lo, L. (2011). Teamwork and Communication in Healthcare. A Literature Review.

Edmonton, Canada. Retrieved from

http://www.patientsafetyinstitute.ca/English/toolsResources/teamworkCommuni cation/Documents/Canadian Framework for Teamwork and Communications Lit Review.pdf

Malterud, K. (2012). Systematic text condensation: a strategy for qualitative analysis. Scandinavian Journal of Public Health, 40(8), 795-805. doi:10.1177/1403494812465030

Maran, N. J., \& Glavin, R. J. (2003). Low- to high-fidelity simulation - a continuum of medical education? Medical Education, 37(s1), 22-28. doi:10.1046/j.13652923.37.s 1.9.x

Meurling, L., Hedman, L., Sandahl, C., Fellander-Tsai, L., \& Wallin, C. J. (2013). Systematic simulation-based team training in a Swedish intensive care unit: a diverse response among critical care professions. BMJ Qual Saf, 22(6), 485-494. doi:10.1136/bmjqs-2012-000994

Morey, J. C., Simon, R., Jay, G. D., Wears, R. L., Salisbury, M., Dukes, K. A., \& Berns, S. D. (2002). Error Reduction and Performance Improvement in the Emergency Department through Formal Teamwork Training: Evaluation Results of the MedTeams Project. Health Services Research, 37(6), 1553-1581. doi:10.1111/1475-6773.01104

Motola, I., Devine, L. a, Chung, H. S., Sullivan, J. E., \& Issenberg, S. B. (2013). Simulation in healthcare education: a best evidence practical guide. AMEE Guide No. 82. Medical Teacher, 35(10), e1511-30. doi:10.3109/0142159X.2013.818632

Murray, W. B., \& Foster, P. A. (2000). Crisis resource management among strangers: principles of organizing a multidisciplinary group for crisis resource management. Journal of Clinical Anesthesia, 12(8), 633-638. doi:10.1016/S0952-8180(00)00223-3

Nestel, D., Tabak, D., Tierney, T., Layat-Burn, C., Robb, A., Clark, S., ... Kneebone, R. (2011). Key challenges in simulated patient programs: an international comparative case study. BMC Medical Education, 11(1), 69. doi:10.1186/1472- 
6920-11-69

Palaganas, J. C., Brunette, V., \& Winslow, B. (2016). Prelicensure Simulation-

Enhanced Interprofessional Education. Simulation in Healthcare, 11(6), 404-418. doi:10.1097/SIH.0000000000000175

Palaganas, J. C., Epps, C., \& Raemer, D. B. (2014). A history of simulation-enhanced interprofessional education. Journal of Interprofessional Care, 28(2), 110-5. doi:10.3109/13561820.2013.869198

Reeves, S., Fletcher, S., Barr, H., Birch, I., Boet, S., Davies, N., ... Kitto, S. (2016). A BEME systematic review of the effects of interprofessional education: BEME Guide No. 39. Medical Teacher, 38(7), 656-668. doi:10.3109/0142159X.2016.1173663

Reeves, S., Goldman, J., Gilbert, J., Tepper, J., Silver, I., Suter, E., \& Zwarenstein, M. (2011). A scoping review to improve conceptual clarity of interprofessional interventions. Journal of Interprofessional Care, 25(3), 167-74. doi:10.3109/13561820.2010.529960

Reeves, S., Pelone, F., Hendry, J., Lock, N., Marshall, J., Pillay, L., \& Wood, R. (2016). Using a meta-ethnographic approach to explore the nature of facilitation and teaching approaches employed in interprofessional education. Medical Teacher, 38(12), 1221-1228. doi:10.1080/0142159X.2016.1210114

Ringen, A. H., Hjortdahl, M., \& Wisborg, T. (2011). Norwegian trauma team leaders-training and experience: a national point prevalence study. Scandinavian Journal of Trauma, Resuscitation and Emergency Medicine, 19, 54. doi:10.1186/1757-7241-19-54

Shapiro, M. J., Morey, J. C., Small, S. D., Langford, V., Kaylor, C. J., Jagminas, L., ... Jay, G. D. (2004). Simulation based teamwork training for emergency department staff: does it improve clinical team performance when added to an existing didactic teamwork curriculum? Quality \& Safety in Health Care, 13(6), 417-421. doi:10.1136/qshc.2003.005447

Shrader, S., Kern, D., Zoller, J., \& Blue, A. (2013). Interprofessional teamwork skills as predictors of clinical outcomes in a simulated healthcare setting. Journal of Allied Health, 42(1), e1-6.

Sigalet, E., Donnon, T., Cheng, A., Cooke, S., Robinson, T., Bissett, W., \& Grant, V. (2013). Development of a team performance scale to assess undergraduate health professionals. Academic Medicine : Journal of the Association of American 
Medical Colleges, 88(7), 989-96. doi:10.1097/ACM.0b013e318294fd45

Stephens, T., Hunningher, A., Mills, H., \& Freeth, D. (2016). An interprofessional training course in crises and human factors for perioperative teams. Journal of Interprofessional Care, 30(5), 685-688. doi:10.1080/13561820.2016.1185096

Stewart, M., Kennedy, N., \& Cuene-Grandidier, H. (2010). Undergraduate interprofessional education using high-fidelity paediatric simulation. Clinical Teacher, 7(2), 90-96. doi:10.1111/j.1743-498X.2010.00351.x

Thannhauser, J., Russell-Mayhew, S., \& Scott, C. (2010). Measures of interprofessional education and collaboration. Journal of Interprofessional Care, 24(4), 336-349. doi:10.3109/13561820903442903

The Joint Commission. (2015). Sentinel Event Data: Root Causes by Event Type 2004 - 2014. Retrieved July 1, 2015, from http://www.jointcommission.org/Sentinel_Event_Statistics/

Thistlethwaite, J., Dallest, K., Moran, M., Dunston, R., Roberts, C., Eley, D., ... Fyfe, S. (2016). Introducing the individual Teamwork Observation and Feedback Tool (iTOFT): Development and description of a new interprofessional teamwork measure. Journal of Interprofessional Care, 30(4), 526-528. doi:10.3109/13561820.2016.1169262

Thomas, E. J., Taggart, B., Crandell, S., Lasky, R. E., Williams, A. L., Love, L. J., ... Helmreich, R. L. (2007). Teaching teamwork during the Neonatal Resuscitation Program: a randomized trial. Journal of Perinatology: Official Journal of the California Perinatal Association, 27(7), 409-14. doi:10.1038/sj.jp.7211771 Tschan, F., Semmer, N. K., Gurtner, A., Bizzari, L., Spychiger, M., Breuer, M., \& Marsch, S. U. (2009). Explicit Reasoning, Confirmation Bias, and Illusory Transactive Memory: A Simulation Study of Group Medical Decision Making. Small Group Research, 40(3), 271-300. doi:10.1177/1046496409332928 Uramatsu, M., Fujisawa, Y., Mizuno, S., Souma, T., Komatsubara, A., \& Miki, T. (2017). Do failures in non-technical skills contribute to fatal medical accidents in Japan? A review of the 2010-2013 national accident reports. BMJ Open, 7(2), e013678. doi:10.1136/bmjopen-2016-013678

van Soeren, M., Devlin-Cop, S., MacMillan, K., Baker, L., Egan-Lee, E., \& Reeves, S. (2011). Simulated interprofessional education: An analysis of teaching and learning processes. Journal of Interprofessional Care, 25(6), 434-440.

doi:10.3109/13561820.2011.592229 
Vogel, S., \& Schwabe, L. (2016). Learning and memory under stress: implications for the classroom. Npj Science of Learning, 1(April), 16011. doi:10.1038/npjscilearn.2016.11

Westli, H. K., Johnsen, B. H., Eid, J., Rasten, I., \& Brattebø, G. (2010). Teamwork skills, shared mental models, and performance in simulated trauma teams: an independent group design. Scandinavian Journal of Trauma, Resuscitation and Emergency Medicine, 18, 47. doi:10.1186/1757-7241-18-47

Wisborg, T., Brattebø, G., Brattebø, J., \& Brinchmann-Hansen, A. (2006). Training multiprofessional trauma teams in Norwegian hospitals using simple and low cost local simulations. Education for Health (Abingdon, England), 19(1), 85-95. doi:10.1080/13576280500534768

Wisborg, T., Brattebø, G., Brinchmann-Hansen, A., Uggen, P. E., Hansen, K. S., \& Norwegian BEST FoundationBEST: Better and Systematic Trauma Care. (2008). Effects of nationwide training of multiprofessional trauma teams in norwegian hospitals. The Journal of Trauma, 64(6), 1613-8. doi:10.1097/TA.0b013e31812eed68

Wisborg, T., Ronning, T. H., Beck, V. B., \& Brattebo, G. (2003). Preparing teams for low-frequency emergencies in Norwegian hospitals. Acta Anaesthesiologica Scandinavica, 47(10), 1248-1250. doi:10.1046/j.1399-6576.2003.00249.x

Wong, A. H.-W., Gang, M., Szyld, D., \& Mahoney, H. (2016). Making an “Attitude Adjustment." Simulation in Healthcare: The Journal of the Society for Simulation in Healthcare, 11(2), 117-125. doi:10.1097/SIH.0000000000000133

Yee, B., Naik, V. N., Joo, H. S., Savoldelli, G. L., Chung, D. Y., Houston, P. L., ... Hamstra, S. J. (2005). Nontechnical skills in anesthesia crisis management with repeated exposure to simulation-based education. Anesthesiology, 103, 241-248. doi:10.1097/00000542-200508000-00006

You, P., Malik, N., Scott, G., \& Fung, K. (2017). Current state of interprofessional education in Canadian medical schools: Findings from a national survey. Journal of Interprofessional Care, O(0), 1-3. doi:10.1080/13561820.2017.1315060

Zhang, C., Thompson, S., \& Miller, C. (2011). A Review of Simulation-Based Interprofessional Education. Clinical Simulation in Nursing, 7(4), e117-e126. doi:10.1016/j.ecns.2010.02.008 